\title{
«UN COLOSO SOBRE LA ARENA»: DEFINIENDO EL CAMINO HACIA LA PLANTACIÓN ESCLAVISTA EN CUBA, 1792-1825
}

POR

\author{
MANUEL BARCIA \\ University of Leeds
}

\begin{abstract}
...la isla de Cuba es un coloso, pero está sobre arena; si permanece erigido es por la constante calma de la atmósfera que le rodea; pero ya tenemos probabilidad de que le agiten fuertes huracanes, y su caída sería tan rápida y espantosa como inevitable, si con anticipación no consolidamos sus cimientos.
\end{abstract}

Félix Varela, 2001: 119

A partir de 1791 las elites criollas de la isla de Cuba comenzaron a tomar ventaja de la situación política en la vecina colonia francesa de Saint-Domingue, a la cual intentaron reemplazar en los mercados internacionales de azúcar y café. Para conseguir sus objetivos fue necesario importar mayores números de esclavos africanos destinados a laborar en las plantaciones. La pelea por el derecho a continuar importando africanos a la isla se libró durante las tres primeras décadas del siglo XIX, no sólo en Cuba y España, sino también en Londres, París y Viena. En este trabajo se discuten y analizan los obstáculos que se presentaron a las elites criollas cubanas a través del periodo, y como de un modo u otro, tanto el aumento de la trata de africanos como el la producción de azúcar fueron asegurados a través de medidas legales e ilegales.

Palabras clave: Cuba, esclavitud, tráfico de esclavos, azúcar.

Cuando el sacerdote habanero Félix Varela escribió las líneas que me he tomado la libertad de usar en el anterior exergo, sabía con meridiana claridad el mensaje que estaba transmitiendo a sus posibles lectores. Hasta el gobierno de Luis de las Casas, comenzado en 1791, la isla de Cuba había sido testigo de cómo se desarrollaba en su región occidental un incipiente modelo plantacio- 
nista, fundamentalmente azucarero, que a partir de la revolución haitiana adquiriría una presencia protagónica dentro de la economía insular. Solamente una década más tarde, a comienzos del nuevo siglo, las continuas transformaciones ocurridas en el mundo occidental habían provocado ya que la colonia antes dependiente del situado de la Nueva España, se colocara entre las primeras productoras-exportadoras de azúcar de caña del mundo, cumpliendo así el sueño de las elites peninsulares de llevar a Cuba por un camino similar al que las Antillas inglesas y francesas habían tomado mucho antes ${ }^{1}$.

Entre 1792 y 1823 el futuro esclavista de Cuba y del imperio español fue discutido ampliamente en varias esferas y lugares americanos y europeos. El hecho de que Cuba siguiera el camino de la gran plantación a partir de 1792 no era al inicio de este periodo un hecho cierto y consumado. De hecho, hubo muchas discusiones que incluso se mezclaron con otros asuntos de importancia, como la invasión napoleónica, las guerras de independencia americanas, el abolicionismo británico, el Trienio Constitucional, la cuestión tecnológica y, sobre todo, la necesidad de traer fuerza de trabajo esclava desde la lejana África. En este trabajo se discute cómo los sacarócratas habaneros consiguieron imponer sus puntos de vista y sus opiniones no solo ante el rey y a pesar de las presiones británicas, sino también ante el resto del imperio español que se opuso a la continuación de la trata de esclavos desde las Cortes de Cádiz. La necesidad de continuar con la trata de africanos se convirtió en una cuestión crucial para los hacendados y mercaderes con intereses en la emergente plantación insular cubana. A través de estos años, liderados por su ideólogo Francisco de Arango y Parreño, estos hombres llevaron sus quejas y reclamos a dondequiera fue preciso, para mantener y desarrollar la trata, a pesar de las presiones británicas para ilegalizarla.

Solamente después de la derrota de las fuerzas liberales en 1823, esta política tratista recibió rienda suelta por parte de la corona sin ser realmente cuestionada otra vez hasta la década de 1860. A pesar de estar comprometido por tratados bilaterales firmados en 1817 y 1835 para terminar la trata, Fernando VII y sus sucesores hicieron la vista gorda y permitieron que la trata no solo continuara, sino que se incrementara exponencialmente, todo para satisfacer los intereses azucareros cubanos.

1 Para los más recientes análisis sobre el tema ver Piqueras, 2009: 273-302; Ghorbal, 2009. 


\section{ORÍGENES DE LA INFRAESTRUCTURA AZUCARERA CUBANA}

Esta historia comienza alrededor de 1762 , cuando la capital insular y una gran parte de la zona occidental habían caído en manos británicas. Debido a la entrada de España en la Guerra de los Siete Años del lado de Francia ${ }^{2}$, Inglaterra se vio con las manos libres para actuar militarmente contra las colonias españolas del Nuevo Mundo. Así, entre agosto de 1762 y julio de 1763, la mitad occidental de Cuba estuvo bajo la égida y los designios de Su Majestad Británica el rey Jorge III. Este hecho tuvo una enorme trascendencia sobre el ulterior desarrollo de la Isla. Los ingleses se convirtieron desde entonces en muestra de lujo del bestiario de los habitantes de la isla de Cuba. A partir de 1763, en cada ocasión que lo requirió, la oligarquía encargada de regir el desarrollo económico, político y social cubanos, echó mano al Peligro Inglés para justificar errores, para conseguir prebendas y para legitimar su política esclavista ${ }^{3}$.

Una sola generación de estos hombres conoció de la firma de la Declaración de Independencia de las Trece Colonias y del surgimiento de la primera república de América, observó pasmada cómo una revolución en Francia le daba la libertad a los esclavos y decapitaba al monarca y a su consorte; ella misma contempló cómo en la vecina y antes exitosa colonia de Saint-Domingue el mundo se ponía de cabeza y, cosa insólita, los esclavos derrotaban a sus amos y comenzaban a gobernar el antiguo territorio borbónico. No escaparon a la mirada de aquellos hombres las campañas napoleónicas y la caída del emperador corso. Hombres como el comerciante riojano Bernabé Martínez de Pinillos ${ }^{4}$ lucraron con la guerra entre las colonias de Norteamérica e Inglaterra,

2 La España de Carlos III entró en la guerra al lado de Francia a causa del Pacto de Familia existente entre los Borbones de ambos lados de los Pirineos. Su intervención fue tardía y desastrosa, nada ganó y sí perdió mucho. Fue, quizá, la peor guerra del juicioso monarca español. Ver Cook, 1996: 28-30; Stone, 1994: 113-117; y también Brumwell, 2001.

3 Ver Ortiz, 1916; Moreno Fraginals, 1978; Murray, 1980; Barcia, 1987; Paquette, 1987.

4 Bernabé Martínez de Pinillos nació en 1752 en el seno de una familia de algún caudal en la localidad riojana de Vigueras. Llega a Cuba a finales de la década de 1770 y, desde 1780 , comercia con toda clase de artículos e insumos, entre los cuales se encontraban vinos de Tenerife, lienzos de Bramante y jabones, por solo citar algunos de la larga y variada lista de productos. En 1790 había alcanzado ya cierta posición dentro de la escala social capitalina, y al elevar los hacendados del occidente de la isla la famosísima carta de protesta contra el Código Negro Carolino, fue Bernabé Martínez de Pinillos uno de los firmantes del documento. A partir del auge tratista y de la intensificación de la producción azucarera, Bernabé comenzó una fructífera carrera refaccionista que lo llevaría a convertirse en uno de los principales comerciantes de esta especie en la isla. En 1795 ocupaba el cargo de consiliario en la Compañía de Seguros Marítimos establecida en La Habana. En 1808, su carrera continuaba en ascenso. En esta fecha era nombrado diputado del Real Consulado y conseguía que su primogénito resultase elegido para 
se hicieron ricos importando negros africanos a expensas del desastre francés en Saint-Domingue, enviaron a la Península a sus hijos -e incluso perdieron a alguno - a la guerra de resistencia contra el invasor francés y terminaron sus días con el pecho cargado de medallas, arrastrando las lanzas y las medias annatas de uno o más títulos nobiliarios y contemplando cómo sus antiguos compañeros en la aventura de la vida iban muriendo a su alrededor, mientras sus hijos se hacían de posiciones cimeras dentro del aparato estatal, religioso o militar de la España fernandina.

Esta fue una época acelerada. Cuba, la colonia hispana que conoció por vez primera en 1762 el bienestar proveniente del comercio libre, no fue ya nunca la misma luego de la partida de los «casacas rojas». Aquella primera generación de hombres de ciencias y letras asumió las riendas de la colonia $\mathrm{y}$, de acuerdo con los incipientes plantadores azucareros y de los algo versados comerciantes de géneros y esclavos, llevó a la Isla a un estado económico, político y social superior. Ellos comenzaron a publicar el primer periódico que circuló en la isla durante años de modo continuo; ellos mejoraron las técnicas de cultivo y se ocuparon de introducir en la isla los últimos adelantos tecnológicos de la época. Para esto incluso enviaron a dos de sus miembros, el conde de Casa Montalvo y Francisco de Arango y Parreño, en una misión científica y política que los llevó a visitar Inglaterra, Jamaica y Saint-Domingue en busca de nuevas tecnologías que pudieran contribuir al desarrollo de la colonias.

La intensificación del tráfico de esclavos africanos, y de su explotación física y extraeconómica, condujo en el occidente cubano al establecimiento de una economía de plantación, fuertemente marcada por el castigo, la represión y el control de aquéllos que eran traídos para asegurar la reproducción constante del ciclo productivo. Para un mejor control de la situación se expidieron reglamentos locales, coloniales y reales, en los que se dejaban claros los deberes y derechos de amos, empleados y esclavos ${ }^{6}$. El objetivo de estos documen-

desempeñar el puesto de apoderado del Ayuntamiento de la Ciudad ante el Consejo de la Regencia, surgido ante la invasión napoleónica del suelo español. Cuando Francisco de Arango y Parreño y el marqués de Someruelos confeccionaron el Memorial para crear una Junta de Gobierno en la capital de la isla, en 1808, fue Bernabé uno de sus 73 firmantes, lo que indica su clara orientación liberal por aquellos momentos. En 1825 recibió la dignidad nobiliaria de primer conde de Villanueva, la cual solamente pudo disfrutar durante cuatro años. Al morir, en 1829, dejó cuantiosos bienes de fortuna - entre ellos dos ingenios - que fueron repartidos entre sus hijos. Su carrera es sólo una de las tantas entre las de otros hombres ambiciosos que, como él, hicieron fama y fortuna en Cuba.

5 Arango, 1936: 21-113.

${ }^{6}$ Un análisis de dichos reglamentos puede ser consultado en Barcia, 1999. 
tos era dejar expedito el camino al despotismo en todo lo referente al manejo de esclavos en la Isla.

Otros documentos, no menos interesantes, fueron apareciendo a lo largo del período. Así, por ejemplo, una interesantísima doctrina cristiana para enseñar a los esclavos bozales la religión de sus dueños salió a la luz ya a fines del siglo XVIII ${ }^{7}$. Los comentarios de los médicos «especialistas» que irían escribiéndose después, a pesar de no ser considerados piezas legales, fueron tenidos en cuenta por los plantadores, así lo demuestran sus reiteradas ediciones $^{8}$.

En este juego de subsistencia y progreso, el futuro cubano fue puesto en manos de tres organismos que centraron las decisiones políticas y económicas de la colonia. Sus integrantes pertenecían a menudo a más de uno de ellos. La más antigua de dichas corporaciones era el Ayuntamiento de La Habana. Esta institución, creada en el siglo XVI, tenía una larga tradición de capacidad para tomar decisiones relacionadas con el futuro de la Isla. En algunas oportunidades sus representantes gozaron de gran influencia ante los capitanes generales e incluso ante los reyes de turno.

Una segunda institución fue la Real Sociedad Patriótica de La Habana, creada en 1793 como parte de la moda ilustrada llegada a Cuba desde Europa. La Real Sociedad se dedicó desde sus primeros momentos a desarrollar las artes, las letras y la agricultura. Como resultado de sus esfuerzos se logró una continuidad en la publicación del Papel Periódico de la Habana, se alcanzaron varios éxitos en materia científica y se promovieron la salud, la educación y el sentimiento de pertenencia a la patria - lo que en este caso significaba, indistintamente, a La Habana o a España.

La tercera corporación que participó de la orgía de crecimiento intelectual y económico de la isla fue el Real Consulado de Agricultura y Comercio, aprobado por Real Cédula de 4 de abril de 1794. Entre los objetivos de esta institución resaltaba la intención de que sirviera para obtener «la más breve y fácil administración de justicia en los pleitos mercantiles, y la protección y fomento de la agricultura y comercio en todos sus ramos $\rangle^{9}$. El Consulado estuvo a cargo del desarrollo económico de la isla de Cuba y es bueno apuntar que durante su existencia no escatimaron sus miembros recurso alguno que pudiese conducirlos al éxito de sus intereses.

7 Laviña, 1989. Ver también «Real Cédula a los oficiales de la Isla de Cuba que tengan mucha cuenta de que los negros vivan cristianamente», en Konetzke, 1953, I: 572.

8 Barrera, 1953. Ver también Chateausalins, 1831; Dumont, 1915 y 1916; Pérez Beato, 1910: 90-93.

9 Marrero, 1971-92, 10: 22. 
Estas tres instituciones clamaron, pidieron, exigieron, protestaron y suplicaron de las Cortes y monarcas cuanto les fue menester. Su leyenda fue muy bien tejida y cada hebra de la madeja fue aprovechada en aras de obtener los adelantos necesarios para la colonia. Numerosos argumentos engrosaron su arsenal a través de los años, entre ellos tuvieron especial éxito aquéllos que resaltaban la extrema fragilidad y falta de protección de la Isla, siempre a merced de las amenazas internacionales y del «salvajismo» de los negros esclavos $^{10}$.

La prosperidad de la colonia y, por extensión, la de estas instituciones estuvo rigurosamente determinada por su capacidad para continuar y, de ser posible, aumentar el tráfico de esclavos africanos a Cuba. Por ello, a pesar de sus quejas sobre el «peligro negro», bien supieron pedir a gritos a comienzos de la década final del siglo XVIII la real orden que les autorizara a introducir esclavos africanos en grandes cantidades. Por esta época comenzaron a solicitar el desestanco del tabaco que frenaba enormemente la industria insular, solicitud que terminó en pertinaz batalla algunos años después ${ }^{11}$. Mientras la América española se sacudía del yugo colonial, Cuba permanecía tan fiel a España que se ganó el oneroso calificativo de Siempre Fiel Isla de Cuba y, aún en 1816, su adulación malintencionada iba tan lejos que concibieron la descabellada idea de cambiar, una vez más, el nombre de la Isla por el de Fernandina, en honor a $\mathrm{Su}$ Majestad Fernando VII ${ }^{12}$. Esta predisposición a congraciarse con quienquiera que mandase en España, los llevó a redactar verdaderos memoriales de humillante súplica ante los diferentes monarcas cada vez que éstos expedían leyes que los perjudicaban.

Claro está que tales documentos no eran meras súplicas, sino que regularmente llevaban implícita una fuerte carga de amenaza de «irremisible pérdida

10 No obstante a su acérrima defensa del tráfico y de la esclavitud misma, los cubanos supieron muy bien lavarse las manos de su responsabilidad en todo lo referente a la esclavitud. Para ello recargaron la culpa a la inconsecuencia de los monarcas que habían permitido y alentado el desarrollo de la esclavitud en América.

11 La batalla por lograr el desestanco del tabaco se extendió hasta 1817, cuando casualmente, coincidiendo con el tratado de abolición de la trata de esclavos con Inglaterra, fue promulgada la Real Orden de 23 de junio que finalmente concedía a Cuba la tantas veces solicitada gracia. Ver: Johnson, 2001: 26-29, 54-57; Sanz, 2009: 151-176.

12 En las actas del cabildo habanero de 1816 se encuentran los acuerdos y la correspondencia con su apoderado ante el rey, Francisco Antonio Rucabado, acerca de este particular. La moción fue denegada por la Corona. Poco después, en el mismo año, intentaron construir una estatua ecuestre del «Rey Felón», proyecto que no llegó a concretarse como inicialmente pensaron, pues la estatua se construyó, pero sin caballo. Estos flirteos con el rey fueron constantes, para más información solamente se necesita consultar las mencionadas actas capitulares, localizadas en el Archivo Histórico de la Oficina del Historiador de la Ciudad de la Habana. 
de la Isla» a manos de los negros esclavos o de la potencia con la cual estuviera en guerra España en cada momento. Por supuesto, ni que decir del omnipresente peligro haitiano, recurrente amenaza que, cual desafiante acero, blandían ante los crédulos ojos de monarcas, regentes y ministros españoles ${ }^{13}$.

El entorno geográfico y las potencias interesadas en la Isla se convirtieron también en eficaces armas en las manos de esta hornada de hombres capaces y emprendedores. Los peligros e influencias a los que estaba sometida Cuba fueron más de temer en sus mentes y en sus escritos que en la realidad. Los tres peligros principales: el inglés, el haitiano y el de una revolución de esclavos y/o libertos, devinieron verdaderas lanzas de combate durante toda la primera mitad del siglo XIX. Los efectos del reiterado uso de temor a estos tres peligros se perciben en la historia de Cuba en un periodo mucho más largo y merecen ser estudiados con más profundidad de lo que lo han sido hasta el momento $^{14}$.

Mientras estos hombres ilustrados pretendían mostrar una imagen prediseñada de Cuba al resto del mundo, en el interior del occidente de la isla las plantaciones azucareras y cafetaleras se hacían dueñas del paisaje rural. La plantación idílica que nos muestran algunas crónicas de viajeros escondía en su oscuro regazo el abuso y la coacción. Esa policroma plantación que aparece retratada en el libro de Justo Germán Cantero, mostraba, al descender a sus cañaverales y plantíos, un espectáculo muy diferente ${ }^{15}$. Allí existía un sistema socio-económico bien estructurado sobre un cuerpo administrativo que encabezaba el amo, y del cual eran miembros activos y con facultades de mando, el administrador, el mayoral, el mayordomo, el boyero, el maestro de azúcar y el contramayoral.

Desde la Vuelta de Abajo hasta la zona de Las Cuatro Villas, la plantación fue una inexcusable presencia en el campo cubano. Entre todas las regiones que figuraron en el desarrollo de la plantación, resaltó la zona matancera. En ella el número de esclavos fue muy elevado desde principios del siglo XIX, lo que provocó que fuera en sus campos donde más abundaran las manifestaciones de resistencia esclava de las que tanto se ha hablado y escrito ${ }^{16}$.

A pesar de la opinión de un viajero inglés en 1820, aún durante muchos años los esclavos continuaron siendo la base principal de las fuerzas productivas de la isla ${ }^{17}$. Para mantener las elevadas cifras productivas que significaban

13 Sobre este tema debe consultarse: Childs, 2006; Ferrer, 58:2 (París, 2003a): 333-356.

14 Sobre la importancia del «peligro haitiano» ver Ferrer, 63:229 (Madrid, 2003b): 675-694, en especial 676-677.

15 Cantero, 1857.

16 Jameson, 1821; Bergad, 1990. 
a la vez enormes ganancias, fue imprescindible el abasto de nuevos esclavos, importados de África o de otras regiones, que realizaran las tareas necesarias dentro de las plantaciones. El tráfico de estos hombres había estado legalizado desde el siglo XVI y en el momento del despegue azucarero cubano nadie sospechaba que un peligro exógeno vendría a constituirse en amenaza de su continuación.

Como si no bastara con el fantasma de la revolución «negra» de Saint-Domingue, un movimiento abolicionista - primero del tráfico de esclavos y luego de la esclavitud - fue tomando fuerza internacionalmente desde finales del siglo XVIII. En 1807 Inglaterra rompió definitivamente con su oscuro pasado tratista para devenir en líder de la crítica al trabajo esclavo. Durante largos años, Inglaterra había sido la gran proveedora de esclavos de toda América. Puertos como Londres, Bristol y, sobre todo, Liverpool, eran considerados los más importantes enclaves de armadores negreros de la cristiandad. Sin embargo, a mediados del siglo XVIII, Inglaterra fue testigo del desarrollo en su propio seno de la Revolución Industrial. Este hecho lo cambiaría todo ${ }^{18}$.

Ciudades como Manchester y Birmingham tomaron el camino del desarrollo industrial, lo que trajo aparejada la introducción de nuevas técnicas y tecnologías de producción y de nuevas concepciones con respecto a cuestiones de tanta importancia como la esclavitud misma. A fines del siglo XVIII, Sir William Pitt se manifestaba, aunque con algunas reservas, en contra del tráfico de esclavos africanos. Más allá iba William Wilberforce, miembro de la Sociedad para la Abolición del Tráfico de Esclavos, fundada en Londres en 1787. Solamente dos años después, en 1789, Wilberforce llevaría directamente ante el Parlamento el asunto ${ }^{19}$. A partir de este año, la poderosa Albión fue escenario de una intensa lucha entre los partidarios de Wilberforce y quienes respaldaban el odioso comercio de africanos. En una década tan tormentosa como la final del siglo XVIII, las idas y venidas del proyecto no tuvieron un éxito defini-

17 «No puede dudarse que la felicidad de las generaciones futuras de cubanos avanzará con la actual abolición. Santo Domingo yace a plena vista de esta isla. Podría pensarse que su terrible historia reciente y su dudoso futuro deberían ser suficientes para impresionar a su vecina con la política y necesidad de aumentar la población blanca. Puedo atestiguar su habilidad para trabajar en este clima. El gran obstáculo al esfuerzo de los blancos es la esclavitud de los negros, que envilece el trabajo manual». Jameson, 1821, 97.

18 Ver, por ejemplo: Williams, 1964, y Blackburn, 1988.

19 La campaña inglesa de abolición del tráfico de esclavos ha sido abordada por muchos autores, ver, por ejemplo, Williams, 1864; Coupland, 1964; Davies, 1966; Asiegbu, 1969; Drescher, 1987. Otros trabajos más recientes que han abordado el tema son los de Jennings, 1997; Oldfield, 1998. 
tivo, a pesar de conseguir algunos adelantos parciales ${ }^{20}$. Solamente en 1804 la cuestión fue tomada en consideración, y el Parlamento sometió el tema a una comisión escogida al efecto. Apenas tres años más tarde, en febrero de 1807, las ideas abolicionistas salían airosas de la larga contienda ${ }^{21}$.

Luego de conseguir la abolición del comercio de esclavos en sus colonias, los abolicionistas ingleses comenzaron una verdadera misión internacional, abocados a la tarea «divina» de eliminar de la faz del mundo occidental la trata negrera. Los motivos de este comportamiento han sido ampliamente discutidos durante casi dos siglos. Algunos historiadores han dado gran relevancia al factor económico del asunto, mientras que otros han buscado en la ideología y la cultura, sus móviles fundamentales.

Sin embargo, a pesar de las razones económicas que marcaron esta proyección internacional de los abolicionistas ingleses, la tan popular entonces palabra filantropía, jugó un papel de gran importancia dentro de la batalla, y más aún, dentro de sus conciencias. Resulta provechoso recordar que la primera sociedad abolicionista se creó en la capital del poderoso Imperio Británico y que la segunda, fundada con el nombre de Amis des Noires en París en 1788, se creó bajo los auspicios de cuáqueros ingleses. Los años que van entre estas fundaciones y la abolición legal del comercio negrero en Inglaterra estuvieron marcados por las interminables y perseverantes luchas de estos hombres que, convencidos del mal que representaba la esclavitud per se, desplegaron todas sus fuerzas en aras de conseguir tan loable fin. Claro está que esta lucha no se limitó a los salones en los cuales solían reunirse los abolicionistas, sino que el pueblo inglés se sumó en pleno al proceso. Quienes una vez apenas prestaron interés al asunto, comenzaron a ponerse al día de sus adelantos, y colaboraron recogiendo firmas y asistiendo a los meetings organizados por las sociedades abolicionistas ${ }^{22}$. Inglaterra fue testigo de uno de los más progresivos y formidables procesos humanistas de la historia. No deben reducirse entonces a un vulgar interés económico los motivos ingleses de abolición internacional de la trata.

20 Blackburn, 1988: 131-160.

21 Ver, entre otros, Anstey, 1975; Drescher, 143 (Oxford, 1994): 136-166; Oldfield, 35: 2 (Cambridge, 1992): 331-343.

22 Murray, 1980: 22-26. 


\section{DEFENDIENDO Y EXPANDIENDO LA TRATA}

Entretanto, la entonces «capital más europea de América» contaba con algunos de los súbditos más brillantes de la época entre todas las colonias de la corona hispana. La negrofobia, ampliamente desplegada desde que los esclavos comenzaron a aparecer como un grupo de peso significativo en las cifras censuales, se venía adueñando día a día del aire que se respiraba en la próspera capital cubana. Sin embargo, esto no era obstáculo para que se siguieran introduciendo africanos destinados al trabajo plantacionista.

Apenas unos meses después de abolirse el tráfico de esclavos en las colonias británicas, el Ayuntamiento habanero expresaba sus más graves preocupaciones en el cabildo ordinario del 22 de enero de 1808. En esta fecha, los miembros de este selecto grupo mostraban su contrariedad frente a las intenciones maquiavélicas del emperador francés, al que casi nunca llamaban por su nombre, tal vez por no invocar el peligro que representaba ${ }^{23}$. La siguiente preocupación venía de un poco más al norte, cruzando el estrecho de La Mancha, venía de Inglaterra. Los habaneros no habían superado aún su pánico ante una posible nueva invasión de los «casacas rojas». La hoy legendaria «hora de los mameyes» no estaba lejos en el tiempo. Ni la imponente fortaleza de San Carlos de la Cabaña, ni las finalmente concluidas murallas de la ciudad, satisfacían lo suficiente a los señores de esta asamblea. Inglaterra parecía acechar constantemente, y esta circunstancia resultaba tan evidente que nadie se atrevía a levantar la voz para cuestionar tan preocupante afirmación. Una última y fundamental inquietud se hacía presente en el diario de dichos hombres. El peligro de una rebelión similar a la ocurrida poco tiempo antes en la vecina Saint-Domingue. El miedo era doblemente dirigido hacia los negros residentes en la isla y hacia aquéllos que podrían invadirla desde el cercano territorio ya emancipado de su Metrópoli. De la preeminencia de este temor quedó para la posteridad el alegato de aquella mañana de enero:

La guerra con Francia no es tan peligrosa como el prodigioso número de nuestros esclavos. No tenemos plazas fuertes (a reserva de la capital) que aseguren una retirada a los Blancos en caso de insurrección de los negros y por consiguiente quedan los campos expuestos a todos los estragos de la crueldad. El exemplo fatal que

23 Resulta particularmente interesante esta circunstancia. Tanto en las actas del cabildo habanero como en la correspondencia de los cubanos que se encontraban en España durante la invasión francesa, escasean notablemente las referencias directas a Napoleón, incluso en los momentos en que se aproximaba su derrota. En las pocas oportunidades que lo mencionaban usaban sus títulos o algún término peyorativo. 
han tomado nuestros esclavos de sus iguales de Santo Domingo: El deseo de la libertad $\mathrm{q}^{\mathrm{e}}$ precisamente debe influir en ellos: El justo fundadísimo recelo de $\mathrm{q}^{\mathrm{e}}$ entre nuestros esclavos se oculten muchos de los $q^{\mathrm{e}}$ prescenciaron y tal vez tubieron parte esencial en la sublevazión del Guarico y $\mathrm{q}^{\mathrm{e}}$ estos le sirvan de promotores y caudillos 24 .

Sin embargo no todo era concierto y armonía en la capital insular. Algunos miembros destacados de la sociedad habanera de la época levantaban sus voces para cuestionar la introducción masiva de esclavos e incluso el tratamiento que se les daba a aquéllos una vez llegados a las plantaciones. El cirujano español Francisco Barrera y Domingo fue uno de ellos. A pesar de nunca ver publicado su manuscrito sobre las enfermedades de los esclavos africanos y los remedios para combatirlas, Barrera y Domingo mantuvo una posición firme en contra del tráfico de esclavos y del tratamiento que se les daba a los esclavos ${ }^{25}$. Aún más ferviente eran las críticas del respetado sacerdote y filósofo habanero José Agustín Caballero, quien arremetió contra la trata de esclavos y los perjuicios que ésta provocaba a la sociedad cubana en una serie de artículos aparecidos en el Papel Periódico de la Habana entre 1791 y $1799^{26}$.

Si los esclavos eran un problema que les quitaba el sueño, la amenaza abolicionista inglesa se iba convirtiendo en un verdadero dolor de cabeza para la oligarquía plantadora criolla. Las presiones del poderoso imperio, comenzadas ya por esta época, fueron seguidas de cerca desde sus primeras manifestaciones por los representantes del Ayuntamiento de La Habana y por sus aliados, los integrantes del Real Consulado de Agricultura y Comercio. En 1809, el ministro inglés en Madrid, John Hookham Frere, era instruido por George Canning, entonces encargado de relaciones exteriores de su Gobierno, de aprovechar cualquier oportunidad para exponer al Gobierno español las razo-

24 AHOHCH. Actas Capitulares Trasuntadas. Libro 75. Folio 18. Cabildo del 22 de enero de 1808. Estos temores fueron explícitos desde el mismo comienzo de la introducción masiva de esclavos africanos en la isla. Ver, por ejemplo, Arango 1888, I: 31-38. Otro ejemplo de estos temores puede verse en la Representación al Rey de los dueños de ingenios de la Habana. ANC: RCJF. 150/7405.

25 Barrera, 1853. Algunos estudios sobre la obra de este personaje son: Flouret, 1985: 141-154; y Martínez Tejero, 2000, I: 373-389. Ver también Barcia, 2003.

26 José Agustín Caballero publicó algunos de estos trabajos bajo varios seudónimos, destacando entre ellos el de El amigo de los esclavos. Ver los artículos: «Nobilísimos cosecheros de azúcar, señores amos de ingenios, mis predilectos paisanos», Papel Periódico de la Habana, 36: 142-144 y 37, 146-147 (1791); «Matrimonios entre esclavos: posterior al 7 de abril de 1796», en Caballero, 1956, II: 3-10; y «De la consideración sobre la esclavitud en este País: informe a la Sociedad Patriótica, 24 de noviembre de 1798», en I: 148-152. Ver también: Le Riverand, 1976; Caballero, 1999. 
nes británicas para abolir la trata. Al año siguiente las presiones continuaron, sin embargo, las condiciones no eran propicias para que la Regencia española, empeñada en organizar la resistencia antinapoleónica a la vez que en conformar un gobierno competente, prestara oídos a una materia tan delicada como ésta ${ }^{27}$.

Sin embargo, todas sus aprehensiones y miedos fueron insuficientes para hacerlos renunciar a la riqueza que vieron en la introducción masiva de esclavos africanos. En fecha tan temprana como 1787, cuatro años antes de que la vecina colonia francesa de Saint-Domingue comenzara a enfrentar la guerra civil que desembocaría en la República de Haití en 1804, el cabildo habanero suplicaba al gobernador de la isla que permitiera importar mayores cantidades de esclavos para trabajar en las plantaciones ${ }^{28}$. Desde 1789 las presiones sobre el nuevo monarca Carlos IV se intensificaron como nunca antes. El rey firmó resolución tras resolución autorizando el tráfico de esclavos y como consecuencia la población esclava pronto rivalizó con la población blanca en las estadísticas de la isla ${ }^{29}$.

Desde 1803 una sociedad anónima fue creada en la capital insular con la intención de participar activamente en el tráfico de esclavos. En una carta al rey enviada aquel mismo año, los suscriptores de esta nueva sociedad le pedían permiso para establecer una casa comercial en Londres o Liverpool desde donde sus negocios podrían ser manejados con más comodidad. En el mismo documento también suplicaban al monarca que les permitiera escoger dos o tres lugares adecuados en la costa de África donde establecer factorías flotantes en los que almacenar sus cargamentos de esclavos hasta llegado el momento oportuno de enviarlos a Cuba. Entre los más destacados accionistas de esta sociedad anónima se encontraban el Real Consulado de Agricultura y Comercio, Pedro y Francisco María de la Cuesta y Manzanal, Tomás de la Cruz Mu-

27 Murray, 1980: 27-28.

28 «Petición del Ayuntamiento de la Habana al Excelentísimo Sr. Gobernador General de un permiso para la introducción de negros, año 1787», El Curioso Americano, 2:1 (1894), pp. 5-8. El Ayuntamiento de La Habana usó de los servicios de la Casa inglesa de Baker and Dawson para introducir esclavos en Cuba desde mediados de los 1780s hasta 1793. Ver Arango, 1888, I: 34-35.

29 Real Cédula concediendo libertad para el comercio de negros con las islas de Cuba, Santo Domingo, Puerto Rico y provincia de Caracas, a españoles y extrangeros, baxo las reglas que se expresan, Madrid, 1789; Real Cédula concediendo libertad para el comercio de negros con los virreynatos de Santa Fé, Buenos Aires, Capitanía General de Caracas e islas de Santo Domingo, Cuba y Puerto Rico, a españoles y extrangeros baxo las reglas que se expresan, Madrid, 1791; Real Cédula para la continuación del comercio de negros, 22 de abril de 1804, Madrid, 1804. 
ñoz, los condes de Jaruco y Casa Bayona, Bernabé Martínez de Pinillos y, por supuesto, Francisco de Arango y Parreño ${ }^{30}$.

Pero llegó el año 1811 y todo se complicó. Justamente a partir de entonces comenzaron los ataques británicos a la trata española. Haciendo lobby e influyendo a algunos diputados a las Cortes constituyentes de 1812, el ministro inglés en la Península, Henry Wellesley, consiguió que el tema saltara a la palestra durante las sesiones celebradas en Cádiz durante la primavera de aquel año. El diputado a Cortes por La Habana, Andrés de Jáuregui, fue el encargado de hacerle frente a las proposiciones de Miguel Guridi y Alcocer y de Agustín de Argüelles. Sus alegatos en defensa del tráfico de esclavos basados en la quasi segura pérdida de la isla de Cuba para la Corona hispana, resultaron lo suficientemente convincentes para que el asunto se discutiera en privado en un primer momento y para que luego resultara archivado ${ }^{31}$.

Por supuesto que antes de que esto sucediera los encargados de dirimir tan delicado asunto debieron atender a las súplicas amenazadoras del capitán general de la isla de Cuba, marqués de Someruelos, y del síndico del Real Consulado de La Habana, Francisco de Arango y Parreño. Ambos escritos resultaron definitorios a la hora de tomar una decisión acerca de este asunto. En aquella ocasión Arango y Parreño clamó, dándole un tono trágico a sus palabras, «Se trata de nuestras vidas, de toda nuestra fortuna, y la de nuestros descendientes (...) Sea lícito á nuestro dolor hablar con esta franqueza; sea lícito á nuestra amargura expresar sus sentimientos con el temple y colorido que tienen nuestros corazones; (...) no es posible que hagan alto en el calor de las frases que á nuestra tribulación se escapen, ni en el vigor de los ataques que hagamos en nuestra defensa» ${ }^{32}$.

Una vez que las fervorosas representaciones de Someruelos y Arango y Parreño fueron conocidas en España, las Cortes concedieron la razón a los plantadores criollos. En 1812 un fortuito acontecimiento vino a complicar todavía más el asunto. Una extensa conspiración con ramificaciones en diferentes pun-

30 Los hacendados y mercaderes de La Havana al Rey Carlos IV. Havana, 12 de enero de 1803. Archivo Nacional de Cuba (ANC). Asuntos Políticos. 106/9. Ver también, Franco, 1991; y Barcia, 2007: 145-158.

31 Murray, 1980: 29.

32 «Representación de la Ciudad de La Habana á las Cortes, el 20 de julio de 1811, con motivo de las proposiciones hechas por D. José Miguel Guridi Alcocer y D. Agustín de Argüelles, sobre el tráfico y esclavitud de los negros; extendida por el Alférez Mayor de la Ciudad, D. Francisco de Arango, por encargo del Ayuntamiento, Consulado y Sociedad Patriótica de la Habana». Arango, 1888, II: 175-176. Aunque el texto fue firmado por una larga lista de figuras notables de la sociedad habanera del momento, el verdadero y único autor del documento fue Arango y Parreño. 
tos de la isla, organizada por libres de color y esclavos fue descubierta en La Habana. Las prevenciones devinieron terror cuando a comienzos de año estallaron varias revueltas de esclavos. Especialmente preocupante fue la ocurrida en el ingenio Peñas Altas, situado a unos pocos kilómetros de la capital. Desde el descubrimiento de la conspiración se culpó a las Cortes de incitar inconsecuentemente al desorden de los esclavos a través de sus inoportunas discusiones acerca de la abolición del tráfico de esclavos. La Conspiración de Aponte, entonces, dio a los habaneros la oportunidad de reafirmar su supuesta razón acerca del tratamiento público que se le había dado al tema en las Cortes. En resumen, tanto Inglaterra como los abolicionistas españoles se vieron obligados a tomarse un receso hasta que las condiciones volvieron a ser propicias para resucitar el tema ${ }^{33}$.

Tras los debates de 1811 la cuestión de la abolición del comercio de esclavos africanos tuvo dos momentos destacados que en gran medida definieron la continuación de la trata hacia Cuba y, por extensión, del crecimiento de la plantación. El primero se desarrolló entre 1813 y 1817, y tuvo como momentos cimeros el Congreso de Viena, celebrado en 1814, y la firma del tratado anglo-español de abolición de la trata, en septiembre de 1817. Un último momento lleno de presiones y nuevos debates puede enmarcarse entre 1821 y 1823, en el corazón del Trienio Constitucional cuando, contra todos los pronósticos, las autoridades coloniales cubanas y los plantadores criollos cuestionaron una vez más la legalidad del tratado de septiembre de 1817.

En 1814 la campaña contra la trata negrera en Inglaterra había vuelto a alcanzar un lugar protagónico, ahora que la amenaza que significaba Napoleón había cesado. El experimentado ministro británico Henry Wellesley sería el encargado de reasumir tales funciones. Guiado esta vez por Lord Castlereagh, Wellesley intentó conseguir, por cuantos medios le fue posible, un pronunciamiento español contra el tráfico de africanos. Sin embargo, la cuestión continuaba siendo sumamente complicada. Las gestiones de Wellesley fracasaron una vez más y el Gobierno de Castlereagh se centró por completo en conseguir, al menos, una declaración abolicionista en el Congreso de Viena ${ }^{34}$.

El temor a un acuerdo definitivo de cese de la trata en Viena hacía padecer a las autoridades e individuos involucrados en el asunto en la lejana isla de Cuba. Mientras transcurrían las sesiones del Congreso, Arango y Parreño, radicado entonces en París, cuestionaba en la prensa escrita la autoridad de los

33 Ver Childs, 2006; Palmié, 2002.

34 Ver Fladeland, 38: 4 (Chicago, 1966): 355-373; Reich, 53:2 (Washington, 1968): 129-143; Murray, 1980: 50-56. 
diputados al Congreso para tomar decisiones trascendentales para el futuro de su isla natal.

Entretanto, Claudio Martínez de Pinillos, apoderado en Madrid del Real Consulado habanero, mantenía a sus compatriotas al tanto de cuanto sucedía en Viena. El primero de noviembre de 1814, en carta escrita en la capital española, hacía un balance de las fuerzas en Europa, determinando que las naciones que miraban con indiferencia el tráfico de esclavos de África eran «por desgracia, las más influyentes» y consideraba más adelante «que el constante empeño y los esfuerzos hechos por los ingleses para cortar este tráfico, como medio directo de destruir nuestra industria agricultura colonial» tenían buena acogida en la capital del Imperio de los Habsburgo ${ }^{35}$.

Muy a pesar de Arango y Parreño y de Martínez de Pinillos, Inglaterra, nación vencedora devenida en árbitro de Europa, consiguió que todas las potencias representadas en el Congreso firmaran una declaración en la cual se condenaba la trata negrera. Claro está que para los esclavistas tan singular documento no significaba nada. Al menos por el momento habían salido airosos. Sin embargo, predeciblemente, Inglaterra no se quedó con los brazos cruzados. A través de su nuevo ministro en España, Charles Vaughan, comenzó a presionar a Fernando VII para conseguir de éste un compromiso de cese del tráfico. La deuda del monarca español con Inglaterra y su manifiesta debilidad ante la máxima potencia militar de la época, provocaron la firma, el 20 de septiembre de 1817, del tratado por el cual España se comprometía a abolir la trata negrera en sus dominios. Como parte de este tratado, el rey de España se comprometía al cese inmediato del comercio de africanos al norte del Ecuador y a la abolición total a partir del 20 de mayo de $1820^{36}$.

35 Claudio Martínez de Pinillos al Prior y Cónsules. Carta n. ${ }^{\circ}$ 66. Madrid, 1 de noviembre de 1814. ANC: GSC. 1099/40587.

36 Tratado entre S.M. el Rey de España y de las Indias y S.M. el Rey del Reino Unido de Gran Bretaña e Irlanda, para la abolición del tráfico de negros, concluido y firmado en Madrid en 23 de setiembre de 1817, Madrid, 1817. El tratado fue hecho efectivo para los dominios españoles por la Real Cédula para la abolición del tráfico de negros concluido y firmado en Madrid, en 23 de setiembre de 1817, Madrid, 1817. Estos documentos pueden hallarse en «Documentos relativos al proyecto de convenio que el gobierno inglés presentó al español para declarar libres á los negros importados de África después del 30 de octubre de 1820», Revista Cubana, 5 (La Habana, 1887): 444-459. 
EL ÚLTIMO RECURSO LEGAL: LA TRATA EN EL TRIENIO CONSTITUCIONAL

El tratado de 1817 no fue cumplido en lo más mínimo, lo cual en realidad constituyó una victoria para los intereses plantacionistas cubanos. La trata, lejos de desaparecer, se intensificó y, según las cifras, en las décadas posteriores a su firma, se recibieron decenas de miles de nuevos esclavos. No obstante, en el mismo año en que se debía producir la abolición total del tráfico de esclavos, la Monarquía española se vio limitada una vez más por la Constitución aprobada ocho años antes en Cádiz. El periodo que hoy conocemos bajo el nombre de Trienio Constitucional trajo como consecuencia inmediata nuevas elecciones de diputados a Cortes.

Aunque la trata había continuado desenfadadamente a pesar de las quejas de Inglaterra, los plantadores criollos, atemorizados por la incertidumbre de que la Corona pudiera compelerlos a cumplir el tratado de 1817, aprovecharon la oportunidad de poder asistir a las Cortes para argüir sus razones esclavistas con el utópico objetivo de invalidar el tratado que, cual espada de Damocles, pendía atemorizante sobre sus cabezas. Dos documentos escritos por sacerdotes acapararon la atención en el periodo. Uno, el más conservador, fue publicado y circuló ampliamente, el otro no. Ambos legitimaban opciones políticas diametralmente opuestas. Sin embargo, para lograr sus fines, empleaban los mismos argumentos. El peligro que representaban Inglaterra y Haití, y los problemas del sistema esclavista cubano. Sus autores fueron los presbíteros cubanos Juan Bernardo O'Gavan y Félix Varela. Estos dos documentos constituyen fuentes imprescindibles para entender las diferentes posturas existentes en Cuba frente al fenómeno de la esclavitud.

O'Gavan llegó a Madrid en 1820 y de inmediato se puso a trabajar en función de los intereses de los plantadores esclavistas criollos, a quienes se encontraba fuertemente vinculado. Como respuesta a una propuesta hecha en las Cortes el 23 de marzo de 1821, de establecer leyes penales capaces de destruir absolutamente el tráfico de negros, escribió su obra clásica, un folleto de apenas 12 páginas que se ha convertido en un texto inevitable y que sirvió a la historiografía cubana en los años posteriores para situarlo en el lugar más bajo dentro de su historia.

Las circunstancias eran ahora bien diferentes a las de 1811. España se hallaba bajo palabra con la Gran Bretaña y, al menos en el papel, resultaba impracticable intentar respaldar el comercio de esclavos africanos. Juan Bernardo O'Gavan, contra todos los pronósticos, fue a Madrid a impugnar el tratado de 1817, utópica intención en un mundo cambiado y en una España sumamente debilitada ${ }^{37}$.

37 El Trienio Constitucional, durante el cual la Constitución de 1812 y las Cortes fueron reinstauradas, comenzó en enero de 1820 con el alzamiento de Cabezas de San Juan. Durante 
Claro está que la impugnación respondía a una encomienda del Real Consulado de La Habana, el cual, en el capítulo séptimo de las instrucciones adjuntas a las observaciones de O'Gavan, clamaba por la ilegitimidad del tratado de 1817:

Por cualquier aspecto que este asunto se mire, se conocerá que en él obró la precipitacion, el mezquino interes, y que no se respetaron derechos sagrados, y se faltó á las consideraciones que dictaba la política, y la justicia, y la verdadera conveniencia pública ${ }^{38}$.

Resaltando el salvajismo de los negros en África y la benevolencia de su vida en Cuba, O'Gavan justificó con razonamientos antropológicos, económicos, sociales y religiosos lo conveniente que sería continuar el tráfico de esclavos a Cuba. No obstante, la razón de más peso expuesta por O'Gavan fue la de la posible escisión de Cuba de los territorios españoles. Para no dejar espacio a dudas, ignoró el tan enarbolado peligro haitiano y reprodujo uno peor, el norteamericano:

Existe un gobierno sabio, liberal en principios, poderoso y activo, que procura estender sobre ella [la isla de Cuba] una mano benéfica, y atraerla por todos medios á su sistema de libertad y engrandecimiento, prodigándola recursos abundantes para su agricultura y comercio... 39

Por supuesto que a O'Gavan le faltó decir que esa nación tan prodigiosa era esclavista. La sentencia del sacerdote santiaguero debió resonar bien clara en los oídos de los diputados, cual profecía de la futura Doctrina Monroe: «Si la arbitrariedad ó la imprudencia de los que mandan no tienen límites, los tiene la paciencia de los pueblos» ${ }^{40}$.

Dos años después llegaba a España, también en calidad de diputado a Cortes, el padre Félix Varela. A diferencia de su antecesor, Varela no se encontraba vinculado a los plantadores criollos que dominaban las instituciones encargadas de regir la vida cubana. Varela era un hombre de reconocida honestidad, nacido en La Habana en 1788 y, al igual que O'Gavan, hombre de confianza del obispo Espada. Su elección había sido respaldada por el prestigioso prelado de la capital cubana. Su actuación en las Cortes, aunque limitada, fue tan

estos tres años hubo varios gobiernos de diferentes tendencias y una apertura a las libertades civiles. La Constitución fue abolida y el rey Fernando VII recuperó todos sus poderes tras la invasión del Duque de Angulema y sus Cien Mil Hijos de San Luis en 1823. Ver Robinson, 1926: 21-46.

38 Estas instrucciones pueden consultarse en O'Gavan, 1821: 12-14.

39 Ibidem: 12.

40 Idem: 12. 
progresista que devino símbolo de las futuras generaciones. Varela llevó dos proyectos a las Cortes, uno de autonomía para la isla de Cuba y otro de abolición gradual de la esclavitud.

Este último se titulaba Memoria para la extinción de la esclavitud en la Isla de Cuba. En este escrito proponía Varela, dejando traslucir intereses claramente humanistas, la abolición gradual de la esclavitud en los dominios españoles con indemnización a sus propietarios. Lo más interesante de la memoria es la novedad, pues Varela clamaba por la abolición de la esclavitud sólo tres años después de haber entrado en vigor el cese legal del tráfico trans-atlántico. Para respaldar su propuesta, la cual nunca pudo ser presentada debido a la caída del régimen constitucional, el sacerdote habanero se vio obligado a valerse de los mismos argumentos que Arango y O'Gavan habían utilizado con anterioridad. O sea, Varela atacó formalmente a Inglaterra, reprodujo los temores a una invasión de la cercana Haití y se hizo eco del peligro de los levantamientos de esclavos.

También criticó Varela la descontrolada introducción de esclavos a la Isla:

De este modo se creyó que podía suplirse sin peligro la falta de brazos, ¡ $\sin$ peligro, con hombres esclavos! El acaecimiento de Santo Domingo advirtió muy pronto al Gobierno el error que había cometido; empero siguió la introducción de negros ${ }^{41}$.

Varela vio el problema más allá, y así pretendía exponerlo:

Resulta, pues, que la agricultura y las demás artes de la isla de Cuba, dependen absolutamente de los originarios de África, y que si esta clase quisiera arruinarnos le bastaría suspender sus trabajos y hacer una nueva resistencia. Su preponderancia puede animar a estos desdichados a solicitar por fuerza lo que por justicia se les niega, que es la libertad y el derecho de ser felices. Hasta ahora se ha creído que su misma rusticidad les hace imposible tal empresa; pero ya vemos que no es tanta, y que, aún cuando lo fuera, serviría ella misma para hacerlos libres, pues el mejor soldado es el más bárbaro cuando tiene quien lo dirija. Pero ¿faltarán directores? Lo hubo en la isla de Santo Domingo, y nuestros oficiales aseguraban haber visto en las filas de los negros los uniformes de una potencia enemiga, cuyos ingenieros dirigían perfectamente todo el plan de hostilidades... ${ }^{42}$

41 Varela, 2001: 114.

42 Ibidem: 2001: 117. Estas líneas varelianas parecen copiadas literalmente del enciclopedista francés Denis Diderot cuando éste afirmó que «Estos relámpagos iluminados anuncian el trueno, y los negros solo carecen de un jefe suficientemente corajudo que los guíe a la venganza y la matanza. Dónde está él, este gran hombre de cuya naturaleza deba tal vez enorgullecerse la especie humana?.» Citado por Benot, 1978: 214; Trouillot, 25: 1-2 (Kingston, 1991): 86-87. 
Sus argumentos eran aterradores aunque no completamente ciertos: «estoy seguro de que el primero que dé el grito de independencia tiene a su favor a casi todos los originarios de África» ${ }^{43}$.

Este escrito de Varela puede considerarse el último de importancia antes de la consagración del modelo plantacionista cubano ${ }^{44}$. Al comenzar 1824 la abolición del tráfico era una obligación internacional de todos los gobiernos y una realidad palpable en la mayor parte del continente americano, con las únicas excepciones de Brasil y Cuba. Las intenciones británicas no habían tenido éxito en la práctica y el tratado de 1817, como luego sucedería con el de 1835 , nunca se cumpliría ${ }^{45}$. Los plantadores criollos siguieron recibiendo sus cargamentos de «sacos de carbón» a pesar de los esfuerzos de los abolicionistas y del gobierno inglés. Las plantaciones finalmente pudieron crecer en la cotidianeidad del paisaje rural del occidente insular del modo que Arango y Parreño y sus acólitos habían deseado desde la última década del siglo anterior. Ya por entonces comenzaban a aparecer ingenios con dotaciones de cientos y cientos de esclavos. Entre 1820 y 1830 entraron ilegalmente en Cuba numerosos cargamentos de esclavos provenientes de África, con los cuales se abastecían las necesidades de mano de obra de las plantaciones.

La infusión tecnológica trajo como consecuencia una mayor productividad de la jornada laboral dentro de estos enormes enclaves. El vapor aplicado al trapiche, las mejoras en los caminos y en las comunicaciones y, por último, la introducción del ferrocarril constituyeron elementos alentadores para la continuación de esta práctica infrahumana. En 1825 los vocablos esclavitud y Cuba se encontraban tan ligados uno y otro, que casi constituían sinónimos. Las facultades omnímodas concedidas a los capitanes generales encargados de gobernar la isla a partir de la restauración de Fernando VII en el trono en 1823, y la creación de la Comisión Militar Permanente de la Isla de Cuba en 1825 eran síntomas claros de la política conservadora de la metrópoli y de la sumisión a la cual la isla estaría sometida en los años por venir ${ }^{46}$. La introducción de esclavos africanos había convertido la zona occidental cubana en una bomba de

43 Ibidem: 2001: 119.

44 Arango intervino en este debate para apoyar a los plantadores. Ver Arango 1823, 2. ${ }^{\text {a }}$ ed.

45 Tratado entre S.M. la reina de España y S.M. el Rey del Reino Unido de Gran Bretaña e Irlanda para la abolición del tráfico de esclavos, concluido y firmado en Madrid en 28 de junio de 1835, La Habana, 1858.

46 Durante estos años fueron descubiertas y reprimidas al menos tres conspiraciones importantes, entre ellas la de los Soles y Rayos de Bolívar en 1823 y la del Águila Negra en 1830 (de esta última ya se conocía en 1825). El control de los esclavos nunca tuvo un lugar secundario. Así, por ejemplo, se reformó en 1824 el Reglamento de Esclavos Cimarrones, publicado por vez primera en 1796. Ver: Reglamento de Cimarrones, 1824. 
tiempo esperando a estallar. Plantadores y comerciantes se habían convertido en esclavos de sus esclavos, y sus ambiciones políticas habían sido limitadas al mínimo, si bien es cierto que sus fortunas aumentaban días tras día ${ }^{47}$. La voluntad de rellenar los bolsillos era ya una tradición. El occidente cubano debería observar todavía, durante más de sesenta años, los horrores de la esclavitud.

\section{BIBLIOGRAFÍA}

Anstey, Roger, The Atlantic slave trade and British Abolition, 1760-1810, Londres, Macmillan, 1975.

Arango y Parreño, Francisco de, Reflexiones de un habanero sobre la independencia de esta Isla, La Habana, Arazoza y Soler, 1823.

Arango y Parreño, Francisco de, Obras, La Habana, Howson y Heinen, 1888.

Arango y Parreño, Francisco de, De la Factoría a la Colonia, La Habana, Secretaría de Educación, 1936.

Asiegbu, Johnson U. J., Slavery and the Politics of Liberation, 1787-1861, Londres, Longmans, 1969.

Barcia Paz, Manuel, Con el látigo de la ira. Legislación, represión y control en las plantaciones cubanas, 1790-1870, La Habana, Ciencias Sociales, 1999.

Barcia, Manuel, «Herencia y Racionalidad. Acerca de la doble moral de los propietarios cubanos de esclavos», Debates Americanos, 9 (La Habana, 2000): 20-26.

Barcia, Manuel, «Middle Passage Afflictions in the Work of Francisco Barrera y Domingo: Literature, Politics and Disease». Ponencia presentada en el congreso internacional Literary Manifestations of the Áfrican Diaspora celebrado en la Universidad de Cape Coast, Ghana, 10-14 noviembre 2003.

Barcia, Manuel, «Sugar and the Legal Trade in Slaves to Havana between 1793 and 1820», Roger Knight, Ulbe Bosma y Juan Giusti (eds.), Sugarlandia Revisited: Sugar and Colonialism in Asia and the Americas, Londres y Nueva York, Berghahn Books, 2007: 145-158.

Barcia, María del Carmen, Burguesía Esclavista y Abolición, La Habana, Ciencias Sociales, 1987.

Barrera y Domingo, Francisco, Reflexiones histórico fisico naturales médico quirúrgicas. Prácticos y especulativos entretenimientos acerca de la vida, usos, costumbres, alimentos, bestidos, color y enfermedades a que propendían los negros de África, venidos á las Américas, La Habana, Ediciones C.R., 1953.

47 Ver, entre otros, Duharte, 1983; Barcia, 9 (La Habana, 2000); y García, 2003. 
Benot, Y., Diderot et l'histoire des deux Indes, ou l'écriture fragmentaire, París, Nizet, 1978.

Bergad, Laird W., Cuban Rural Society in the Nineteenth Century. The Social and Economic History of Monoculture in Matanzas, Princeton, Princeton University Press, 1990.

Blackburn, Robin, The Overthrow of Colonial Slavery, Londres, Verso, 1988.

Brumwell, Stephen, Redcoats: The British Soldier \& War in the Americas, 1755-1763, Cambridge, Cambridge University Press, 2001.

Caballero, José Agustín, Escritos varios, La Habana, Universidad de La Habana, 1956.

Caballero, José Agustín, Obras, La Habana, Imagen Contemporánea, 1999. Introducción a cargo de Edelberto Leyva.

Cantero, Justo Germán, Los ingenios. Colección de vistas de los principales ingenios de azúcar de la isla de Cuba, La Habana, Litografía de Luis Maquier, 1857.

Chateausalins, Bernardo Honorato de, El vademecum de los hacendados cubanos, Nueva York, s.e., 1831.

Childs, Matt D., The 1812 Aponte Rebellion in Cuba and the Struggle against Atlantic Slavery, Chapel Hill, The University of North Carolina Press, 2006.

Cook, Don, The Long Fuse: How England Lost the American Colonies, 1760-1785, Nueva York, Atlantic Monthly Press, 1996.

Coupland, Reginald, The British Anti-Slavery Movement, Londres, Barnes \& Noble, 1964.

Davies, David Brion, The Problem of Slavery in the Age of Revolution, 1770-1823, Ithaca, Cornell University Press, 1966.

Drescher, Seymour, Econocide. British slavery in the era of abolition, Pittsburgh, University of Pittsburgh Press, 1977.

Drescher, Seymour, Capitalism and Anti-Slavery. British Abolitionism in Comparative Perspective, Oxford, Oxford University Press, 1987.

Drescher, Seymour, «Whose Abolition? Popular Pressure and the Ending of the British Slave Trade», Past and Present, 143 (Oxford, 1994): 136-166.

Duharte Jiménez, Rafael, «La situación política en la primera mitad del siglo XIX», Seis ensayos de interpretación histórica, Santiago de Cuba, Editorial Oriente, 1983.

Ferrer, Ada, «La société esclavagiste cubaine et la révolution haïtienne», Annales, 58/2 (París, 2003a): 333-356.

Ferrer, Ada, «Noticias de Haití en Cuba», Revista de Indias, 63/229 (Madrid, 2003b): 675-694. 
Fladeland, Betty, «Abolitionist Pressures on the Concert of Europe, 1814-1822», The Journal of Modern History, 38/4 (Chicago, 1966): 355-373.

Flouret, Michele, «Un precurseur de la médecine psychosomatique en 1798: Francisco Barrera y Domingo, médecin des esclaves a Cuba», J. M. Racault y A. J. Bullier (eds.), Pratiques du Corps: Médecine, Hygiène, Alimentation, Sexualité, Réunion, Université de Réunion, 1985: 141-154.

Franco, José Luciano, Comercio Clandestino de Esclavos, La Habana, Ciencias Sociales, 1991.

García, Gloria, Conspiraciones y Revueltas: La actividad política de los negros en Cuba, 1790-1845, Santiago de Cuba, Editorial Oriente, 2003.

Ghorbal, Karim, Rèformisme et esclavage à Cuba, 1835-1845, París, Publibook, 2009.

Henri Dumont, «Antropología y patología comparada de los negros esclavos. Memoria inédita referente a Cuba», Revista Bimestre Cubana, números correspondientes a los años 1915 y 1916, La Habana.

Jameson, Robert, Letters from the Havana, during the year 1820. Containing an account of the present state of the island of Cuba, and observations on the slave trade, Londres, J. Miller, 1821.

Jennings, Judith (ed.), The Business of abolishing the British slave trade, 1783-1807, Londres, Frank Cass, 1997.

Johnson, Sherry, The Social Transformation of Eighteenth-Century Cuba, Gainesvi1le, University Press of Florida, 2001.

Konetzke, Richard, Colección de documentos para la historia de la formación social de Hispanoamérica, 1493-1810, Madrid, CSIC, 1953.

Laviña, Javier, Doctrina para negros. Explicación de la doctrina cristiana acomodada a la capacidad de los negros bozales. Nicolás Duque de Estrada, Barcelona, Sendai, 1989.

Le Riverand, Julio, «Conciencia de la contradicción. El Padre Caballero y la esclavitud», Santiago, 23 (Santiago de Cuba, 1976): 173-180.

Marrero, Leví, Cuba: Economía y Sociedad. Azúcar, Ilustración y conciencia (1763-1868), Madrid, Playor, 1971-1992, 15 vols.

Martínez Tejero, Vicente, «Un ilustrado aragonés en Cuba: Francisco Barrera, cirujano y naturalista», J. A. Ferrer Benimelli y otros, El Conde de Aranda y su tiempo, Zaragoza, Universidad de Zaragoza, 2000, I: 373-389.

Moreno Fraginals, Manuel, El Ingenio. Complejo económico-social del azúcar, La Habana, Ciencias Sociales, 1978.

Murray, David Odious Commerce. Britain, Spaniard the Abolition of the Cuban Slave Trade, Cambridge y Nueva York, Cambridge University Press, 1980. 
O’Gavan, Juan Bernardo, Observaciones sobre la suerte de los negros del África, considerados en su propia patria y trasplantados á las Antillas Españolas y Reclamación contra el tratado celebrado con los ingleses en el año de 1817, Madrid, 1821.

Oldfield, J. R., «The London Committee and Mobilization of Public Opinion against the Slave Trade», The Historical Journal, 35/2 (Cambridge, 1992): 331-343.

Oldfield, J. R., Popular Politics and British Anti-Slavery. The Mobilisation of Public Opinion against the Slave Trade, 1787-1807, Londres y Portland, Or., Frank Cass, 1998.

Ortiz, Fernando, Los negros esclavos, La Habana, Revista Bimestre Cubana, 1916.

Palmié, Stephan, Wizards and Scientists: Explorations in Afro-Cuban Modernity, Durham, NC., Duke University Press, 2002.

Paquette, Robert L., Sugar is Made with Blood: The Conspiracy of La Escalera and the conflict between Empires over Slavery in Cuba, Westport, Conn., Wesleyan University Press, 1987.

Pérez Beato, Manuel, «Datos para la historia de la medicina en Cuba», El Curioso Americano, 4/3-4 (La Habana, mayo-agosto de 1910): 90-93.

Piqueras, José Antonio, «La vida política entre 1780 y 1878», Consuelo Naranjo Orovio (coord.), Historia de Cuba, Madrid, CSIC-Doce Calles, 2009: 273-302.

Reglamento de Cimarrones, La Habana, 1824.

Reich, Jerome, «The Slave Trade at the Congress of Vienna - A Study in English Public Opinion», The Journal of Negro History, 53/2 (Washington, 1968): 129-143.

Sanz Rozalén, Vicent, «Los negros del rey. Tabaco y esclavitud en Cuba a comienzos del siglo XIX», José A. Piqueras (ed.), Trabajo libre y coactivo en sociedades de plantación, Madrid, Siglo XXI, 2009: 151-176.

Spence Robinson, William, "The Policy of Spain toward Its Revolted Colonies, 1820-1823», Hispanic American Historical Review, 6/1-3 (1926): 21-46.

Stone, Bailey, The Genesis of the French Revolution, Cambridge, Cambridge University Press, 1994.

Trouillot, Michel-Rolph, "“From Planters” Journals to Academia: The Haitian Revolution as Unthinkable History», The Journal of Caribbean History, 25/1-2 (Kingston, 1991): 86-87.

Varela, Félix, «Memoria que demuestra la necesidad de extinguir la esclavitud de los negros en la isla de Cuba, atendiendo a los intereses de sus propietarios», Obras, II, La Habana, Imágen Contemporánea, 2001: 113-119.

Williams, Eric, Capitalism and Slavery, Londres, Trafalgar Square Publishing, 1964.

Fecha de recepción: 6-6-2010

Fecha de aceptación: 15-8-2010 


\section{«A GIANT BUILT ON SAND»: PAVING THE ROAD TOWARDS THE SLAVE PLANTATION IN CUBA, 1792-1825}

From 1791 on, the Creole elite on the island of Cuba started taking advantage of the political situation on the neighboring island of Saint-Domingue, which they had tried to replace on the sugar and coffee markets. To reach their objectives it was necessary to import greater numbers of African slaves to put to work on the plantations. The battle for the right to keep importing Africans to the island was fought during the first three decades of the 19th century, not only in Cuba and Spain, but also in London, Paris and Vienna. This article discusses and analyses the obstacles the Cuban Creole elite encountered throughout the period, and how, one way or another, both the increase in the slave trade and sugar production were ensured through legal and illegal measures.

KEY WORDS: Cuba, slavery, slave trade, sugar. 